\title{
A UBERIZAÇÃO DO TRABALHO HUMANO DIANTE DOS PRINCÍPIOS FORMADORES DO DIREITO DO TRABALHO E DAS DECISÕES DO TRIBUNAL SUPERIOR DO TRABALHO
}

\author{
Mario Sergio Dias Xavier ${ }^{1}$ \\ José Alexandre Ricciardi Sbizera ${ }^{2}$
}

Resumo: O artigo aborda espécie de novas relações e negócios que invadem a sociedade usando plataformas digitais e internet para a prestação de serviços, em especial modelos de negócios de transporte como a UBER. Através do método hipotético-dedutivo, se investiga aqui o fenômeno social vinculado às relações de trabalho, denominado de Uberização e como este fenômeno se encaixa juridicamente quando confrontado com os princípios formadores do Direito do Trabalho em comparação com a legislação e de julgamentos do TST. O objetivo, portanto, é identificar se a Uberização é, de fato, modalidade de economia de compartilhamento, em sua forma conceitual.

Palavras-Chave: Direitos Humanos. Ocupação. Relações de emprego. Revolução 4.0. Direito, Sociedade e Tecnologia.

\section{THE UBERIZATION OF HUMAN LABOR BEFORE THE PRINCIPLES THAT FORM THE LAW OF LABOR AND THE DECISIONS OF THE SUPERIOR LABOR COURT}

Abstract: The article addresses a kind of new relationships and businesses that invade society using digital platforms and the internet for the provision of services, in particular transport business models such as UBER. Through the hypothetical-deductive method, we investigate here the social phenomenon linked to labor relations, called Uberization and how this phenomenon fits legally when confronted with the principles that form Labor Law in comparison with the legislation and judgments of the TST. The objective, therefore, is to identify whether Uberization is, in fact, a sharing economy modality, in its conceptual form.

Key words: Human Rights. Occupation. Labor relationships. 4.0 Revolution. Law, Society and Technology.

\section{INTRODUÇÃO}

\footnotetext{
${ }^{1}$ Mestrando em Direito, Sociedade e Tecnologias pelas Faculdades Londrina. Bacharel em Direito pela Universidade Estadual de Londrina. Advogado Trabalhista e Vice-Presidente da OAB Subseção Londrina. Endereço eletrônico: mario@maxavier.adv.br

${ }^{2}$ Mestre e Doutor em Direito pelo Universidade Federal de Santa Catarina - UFSC. Professor do Mestrado Profissional em Direito, Sociedade e Tecnologias da Escola de Direito das Faculdades Londrina e do Curso de Graduação em Direito das Faculdades Integradas Vale do Ivaí - Univale. Endereço eletrônico: jarsbizera@gmail.com
} 
A sociedade da tecnologia e informação inova e avança em uma velocidade impressionante, tão veloz que o objeto deste artigo pode se tornar perdido no tempo quando já se fala em Uber utilizando-se de carros autônomos, sem uso de motorista ser humano como prestador de serviço. Mesmo assim, entende-se que ainda se faz necessária (talvez não por muito mais tempo) discussão sobre a forma e natureza jurídica da prestação de serviços do trabalhador motorista para a Uber.

Em outras palavras, é necessário verificar se de fato a empresa é mera intermediadora de mão de obra, servindo de plataforma de aproximação entre o prestador e o tomador dos serviços, ou seja, entre o motorista e o passageiro ou revela-se apenas um empregador que se utiliza de véu protetor para ocultar a presença de uma relação de emprego.

Dentre tantas plataformas, que nasceram de uma ideia de economia de compartilhamento (ainda que desvirtuada, como é defendido neste artigo), trata-se especificamente da plataforma UBER, na medida em que é a referência mais conhecida e origem de um fenômeno de prestação de serviços denominado de UBERIZAÇÃO.

Para tanto, abordaremos aqui alguns dados públicos da uber e da conceituação de uberização como instrumento de precarização das condições de trabalho, analisando algumas características formais do contrato entre empresa e motorista em contraposição à prática da rotina de trabalho deste último. Além disso, realiza uma análise comparativa da legislação brasileira, dos princípios que regem esse ramo do Direito com os julgamentos da mais alta corte trabalhista no País, o Tribunal Superior do Trabalho.

Com estes destaques e objetos de análise, pretende-se identificar, como acima apontado, o que há de novo e o que há do mesmo na relação de trabalho entre UBER e motorista. Questiona-se, pois, se há a presença de trabalho autônomo em economia de compartilhamento ou de contrato de emprego.

Além de pesquisa biográfica junto à doutrina, legislação e sítios eletrônicos, bem como análise nas bases de dados como Portal de Periódicos do CAPES, dentre outras, este artigo utiliza-se de decisões judiciais proferidas pelo Tribunal Superior do Trabalho, com o objetivo apontar, a partir do Direito Material e dos Princípios em que se se funda, a natureza jurídica da relação dos motoristas de aplicativo com a uber.

\section{A REVOLUÇÃO 4.0 E O FENÔMENO UBERIZAÇÃO}


Ainda que de forma tangencial, cumpre tratar do crescente avanço científico somado ao aprimoramento de novas ciências, que proporcionou forte desenvolvimento de novas tecnologias, fazendo com que a sociedade se transformasse rapidamente e as relações humanas, consequentemente, fossem influenciadas, especialmente com o advento dos mais diversos aplicativos, que são responsáveis por influenciarem o convívio interpessoal diariamente, impactando diretamente o tecido coletivo.

Desse modo, não há como se falar do escopo da presente pesquisa sem que, previamente, haja uma análise do nascimento do conceito "uberização". Preliminarmente, portanto, é necessário abordar o momento no qual estamos inseridos, cujos cientistas já têm se referido como a Quarta Revolução Industrial ou também denominada como Revolução Industrial 4.0.

\begin{abstract}
Estamos a bordo de uma revolução tecnológica que transformará fundamentalmente a forma como vivemos, trabalhamos e nos relacionamos. Em sua escala, alcance e complexidade, a transformação será diferente de qualquer coisa que o ser humano tenha experimentado antes (...) A quarta revolução industrial não é definida por um conjunto de tecnologias emergentes em si mesmas, mas a transição em direção a novos sistemas que foram construídos sobre a infraestrutura da revolução digital (anterior). (SCHWAB, 2016, p. 26).
\end{abstract}

Diante desse panorama, a Revolução Industrial 4.0 pressupõe o início de um período marcado por uma base tecnológica já arraigada onde ocorre subversão dos moldes do funcionamento do corpo coletivo, culminando, pois, na geração de um novo espaço, ao qual os indivíduos precisam se adaptar, pois no avanço tecnológico não haverá retrocesso.

A aceleração tecnológica talvez seja a forma de aceleração mais óbvia e mais perceptível entre as pessoas. Klaus Schwab sustenta que o século XXI está sendo marcado pela Revolução 4.0, uma acentuada revolução tecnológica, caracterizada pela sua velocidade, amplitude, profundidade e impacto sistêmico. A Quarta Revolução Industrial, como também é conhecida, unirá os mundos físico, biológico e digital, o que ocorrerá, segundo o autor, em um ritmo exponencial, não linear, uma vez que as novas tecnologias impulsionam ainda mais inovações (SCHWAB, 2016, pg. 12-13.23).

As inovações tecnológicas e as transformações sociais estão intimamente relacionadas, sendo bastante difícil pensar em um novo equipamento que não tenha sequer modificado, mesmo de forma tímida, o modo de um indivíduo realizar determinada atividade, 
sendo o fator tempo um dos principais motivadores, uma vez que as tecnologias fazem com que determinadas funções sejam efetuadas de maneira mais ágil.

Dessa forma, assim como os elementos produtivos básicos à própria indústria 4.0 estariam a ser extraídos da periferia (países do sul) em condições gravosamente precárias, o mesmo processo de informatização das relações estaria a alimentar o surgimento de postos de trabalho em um setor de serviços composto pelo que denomina "intermitentes globais": trabalhadores que, para fugir do desemprego, colocam-se em situação de permanente disponibilidade para, sob o manto do empreendedorismo, fruírem do "privilégio da servidão". (ANTUNES, 2018).

A organização do trabalho, portanto, sofre bastante impacto em sua dinâmica com o advento da globalização, visto que como o presente está cada vez mais reduzido e fugaz, o conceito de profissão é alterado, crescendo o fluxo de trabalhos com alta rotatividade ou "temporários", de modo a valorizar a experiência em diversas atividades distintas.

No compasso da aceleração social e intensificação do ritmo cotidiano, as plataformas digitais surgem para oferecer aos prestadores de serviço a possibilidade de autocontrole de seu tempo. Assim, os trabalhadores, denominados como autônomos, possuem a falsa sensação, como se verá adiante, de que estão livres para determinar o horário disponível para fornecer o seu serviço.

Sendo assim, como o advento tecnológico não sofrerá retrocesso, existe a necessidade de adaptação às novas tecnologias, visto que estas estão diretamente presentes no nosso cotidiano. Logo, as empresas têm se modernizado, no sentido de que, com as novas modernidades, enquanto uma grande empresa precisa de estabelecimento comercial, pessoal especializado, gastos materiais, entre outros, as novas empresas necessitam de menos recursos para operar.

Destarte, a denominação de "Uberização" está intimamente ligada aos conceitos de consumo coletivo e de economia do compartilhamento. Para Shirky (2012, apud SILVEIRA et al., 2016), a economia compartilhada surge nos Estados Unidos da América em 1990, resultado do impulsionamento dos avanços tecnológicos que possibilitaram a redução dos custos das transações online.

Schor (2014, apud SILVEIRA et al., 2016) completa o raciocínio sob a alegação de que tal fator foi determinante no sentido de viabilizar a criação de novos modelos de negócios tendo como base o compartilhamento de bens e serviços entre pessoas desconhecidas. 
O avanço dos meios tecnológicos abre cada vez mais espaço para o crescimento dessa modalidade de comércio. Gansky (2010, apud SILVEIRA et al., 2016) define economia compartilhada como:

Uma nova tendência que se expande por meio de novas organizações e novo modelos de negócio, com foco no compartilhamento. É considerado um sistema socioeconômico construído em torno do compartilhamento de recursos humanos e físicos, o qual inclui a criação, produção, distribuição, o comércio e o consumo compartilhado de bens e serviços por pessoas e organizações (p. 300).

Todavia, é importante pontuar que a relação de trabalho entre a empresa Uber e seus motoristas são marcadas pela precariedade, porquanto a partir do momento em que seus funcionários deixam de serem considerados como empregados para serem "parceiros" ou autônomos", passa a existir uma desvirtuação da relação empregatícia.

A empresa vende a falsa ideia de que o parceiro é um autônomo e que trabalhará por conta própria, portanto, terá uma jornada livre, pois seu salário será auferido mediante a própria produção, isto é, dependendo do número de corridas realizadas e a quantidade de dias trabalhados.

\section{A EMPRESA UBER}

A UBER é uma empresa criada no ano de 2009, que, nada obstante ser gerada na onda do fenômeno de Economia de Compartilhamento que se alastrou pelo Vale do Silício Califórnia, nos Estados Unidos, criou um método de atividade lucrativo e comercial, que nada se assemelha ao conceito original de sharing economy.

A economia do compartilhamento emergiu e tornou-se expressiva no contexto da revolução digital, crise econômica mundial e desemprego, sendo uma alternativa de renda e sobrevivência imediata dos trabalhadores, enquanto os consumidores enxergam vantagens econômicas na sobreposição do "usar" em detrimento do "ter", afinal, por qual razão comprar um carro - que pressupõe saber dirigir, possuir habilitação, gastos com manutenção e combustível, seguros, etc - se podemos pedir um carro com poucos toques no celular, por um preço baixo? Emergem questionamentos se é economicamente viável possuir um automóvel quando se compara às vantagens dos apps que intermediam serviços de transporte, como a Uber (SAMUELSON, 2017).

A uberização (BOUDAUD, 2015) simboliza as mais recentes inovações nos serviços pela Uber, marcando uma intensa ruptura com a antiga estrutura de intermediação, CONPEDI LAW REVIEW | EVENTO VIRTUAL | v. 7 | n. 1 | p. 75 - 94 | JAN - JUN | 2021 
fragmentação, hierarquização e determinação de funções e responsabilidades ao longo da complexa cadeia produtiva de determinada mercadoria.

Uber:

Na obra "Uberização: a nova onda do trabalho precarizado", Tom Slee aponta que a

[...] Se apoia em plataformas de software, páginas de internet e aplicativos de celular para conectar consumidores com fornecedores e ficar com uma fatia dos ganhos. O software também faz a medição dos pagamentos e provê um sistema de reputação que, dizem eles, resolve o problema de triagem. Assim, estranhos podem confiar uns nos autos. (SLEE, 2017, p. 39).

A uber, pois, criou um aplicativo, uma plataforma de serviço de transporte, com objetivo de lucro, permitindo que motoristas e passageiros, respectivamente, prestadores de serviços e clientes, se encontrem no mundo físico. De tal sorte, que a uber, no campo formal, se apresenta como uma plataforma digital de aproximação entre o motorista, prestador de serviços, e o passageiro cliente.

Assim é que, na visão da empresa, o cliente da uber é o motorista e não o passageiro. É o motorista que pagaria a uber pela intermediação com o passageiro e o não o contrário. O motorista seria autônomo, "dono" do seu próprio negócio, assumindo todo o custo e risco do empreendimento, utilizando-se da plataforma quando bem entendesse, para facilitar a conexão com seu cliente passageiro, sem qualquer exigência de frequência, habitualidade, fixação de jornada de trabalho ou qualquer forma de submetimento jurídico.

A conclusão, segundo esta visão, seria de que o Motorista trabalho pelo aplicativo e não para o aplicativo.

No entanto, não se pode relevar circunstâncias importantes para identificar a relação entre a uber e o motorista. São elas: a) Há um contrato de adesão proposto pela uber, cujas cláusulas não podem ser questionadas ou negociadas pelo motorista; b) O aplicativo controla e fiscaliza a prestação de serviços, indicando padrões de conduta, do veículo utilizado no transporte e vestimentas; c) O aplicativo adota sistema de avaliação do motorista e prevê, contratualmente, possibilidade de rescisão contratual de forma unilateral pela empresa; d) $\mathrm{O}$ aplicativo indica bônus para motoristas que trabalhem em dias, horários e regiões fixadas pela empresa, adotando claro instrumento de recompensa para implementação de habitualidade; e) O aplicativo que fixa o preço a ser cobrado para a viagem.

Ainda nesse sentido, no sítio help.uber.com, reside orientações para o passageiro apresentar reclamações para a uber contra o motorista, o que indica, claramente, contradição 
no argumento de que o passageiro não e cliente do aplicativo. Neste mesmo sítio, há opções para o passageiro reclamar de cobranças mal feitas pelo motorista, quando a cobrança ultrapassa o valor indicado pelo aplicativo, bem como quando o motorista não se apresenta de forma profissional.

Coloca-se à lume, pois, que a uber ultrapassa o limite de mera vendedora de aplicativo de intermediação, apresentando-se em atividade comercial de transporte, tomando força de trabalho do motorista, que a ela se submete.

O trabalho uberizado, percebe-se, é o produto não acabado de um processo de substantiva transformação no padrão de acumulação capitalista, amparado no esgotamento do fordismo, mudança no padrão tecnológico, fim do acordo de Bretton Woods, integração dos mercados em escala global e livre movimentação de capitais (OLIVEIRA, 2015).

Nesse âmbito, o caminho da automação utilizado para implementar a economia de plataforma, foi induzido com o objetivo de angariar ganhos de produtividade amparados na eficiência do mercado, com fundamento no pensamento econômico neoliberal.

Alicerçado no pensamento econômico novo-clássico e em outras variações do pensamento liberal, o neoliberalismo vê o desemprego como apenas o resultado de escolhas racionais de indivíduos calculando a melhor posição entre a desutilidade marginal do trabalho e a satisfação com o salário real (SOUSA, 2017).

Na visão neoclássica não existe explicação para o desemprego involuntário, a não ser a rigidez e desequilíbrios dos mercados, os quais podem ser ocasionados pela ineficiente interferência do Estado na economia, bem como de outras instituições, como por exemplo, os sindicatos. Logo, seguindo essa corrente, um dos elementos dessa interferência ineficiente supracitada diz respeito aos Direitos Trabalhistas e seus princípios.

Nessa seara, ao se analisar o contexto do trabalho dos motoristas da empresa Uber, verifica-se que tais trabalhadores estão suscetíveis a um modelo laboral que comporta abusos, como, por exemplo, jornadas excessivas, diante da inexistência de limitação da duração do trabalho.

Existem doutrinadores, contudo, que defendem a existência do vínculo empregatício nesse sistema de economia laborativa, arguindo que existem elementos presentes na relação aptos a constituírem como relação de emprego, sob o fundamento de que existem regras de conduta estabelecidas de forma unilateral, preços fixados pela empresa sem qualquer opinião dos motoristas, estabelecimento dos padrões a serem seguidos e a inexistência de 
possibilidade de se alavancar empreendimentos diversos e que a qualquer tempo os prestados de serviços podem ser desligados do aplicativo. (TODOLÍ-SIGNES, 2015, apud PELLEGRINI, 2017).

Diante disso, criar medidas de harmonização entre as novas possibilidades de trabalho e a tutela dos direitos fundamentais mínimos dos trabalhadores, torna-se um desafio para o Direito do Trabalho no cenário contemporâneo. Segundo Arun, é o início da transição do trabalho para a economia colaborativa, o que impossibilita a criação de leis trabalhistas específicas. Isso porque, geralmente, legislações trabalhistas duram décadas, e a inexistência de dados suficientes para o trabalho na economia colaborativa dificulta a elaboração de medidas em longo prazo (SUNDARARAJAN, 2016).

Tal ideia de negócio empresarial, que se utiliza de mão de obra apontada teoricamente como autônoma e com transferência do custo e risco do negócio, bem como do patrimônio para o prestador de serviço, vem recebendo na doutrina o nome de Uberização do trabalho, que nada mais é do que a precarização do trabalho

Contudo, em que pese haja o fenômeno da Uberização, não se pode deixar que a roupagem de intermediação da demanda por meio de uma plataforma online seja um empecilho para a garantia de direitos fundamentais a esses trabalhadores que se implicam de modo dependente e subordinado em processos de trabalho que geram riqueza para as empresas-aplicativo.

A busca por justiça social do Direito do Trabalho atrelada aos seus princípios protetores, bem como suas categorias de proteção, devem alcançar também a esses vulneráveis denominados falsamente de "autônomos" e "empreendedores", para que possam ter assegurado um trabalho com dignidade humana.

\section{JULGAMENTOS DO TRIBUNAL SUPERIOR DO TRABALHO}

Como fenômeno recente, a uberização da relação de trabalho não acendeu ainda ao Tribunal Superior do Trabalho em volume suficiente para produção de jurisprudência pacífica sobre o tema.

As dificuldades processuais para a admissão e seguimento do Recurso de Revista, previstas no artigo 896 da CLT, também impedem a análise meritória da Alta Corte 
Trabalhista em grande volume sobre o tema. Daí porque há relativa pouquidão de decisões

sobre a natureza jurídica do trabalho na uber.

De qualquer forma, transcreve-se abaixo duas ementas oriundas, respectivamente, da

Quarta e Quinta Turmas do Tribunal Superior do Trabalho. São elas:

AGRAVO DE INSTRUMENTO EM RECURSO DE REVISTA. ACÓRDÃO PUBLICADO NA VIGÊNCIA DA LEI N. 13.015/2014. VÍNCULO DE EMPREGO. MOTORISTA. UBER. AUSÊNCIA DE SUBORDINAÇÃO. Em razão de provável caracterização de ofensa ao art. $3^{\circ}$, da CLT, dá-se provimento ao agravo de instrumento para determinar o prosseguimento do recurso de revista. Agravo de Instrumento provido. RECURSO DE REVISTA. ACÓRDÃO PUBLICADO NA VIGÊNCIA DA LEI N. 13.015/2014. VÍNCULO DE EMPREGO. MOTORISTA. UBER. AUSÊNCIA DE SUBORDINAÇÃO. TRANSCENDÊNCIA JURÍDICA RECONHECIDA. Destaque-se, de início, que o reexame do caso não demanda o revolvimento de fatos e provas dos autos, isso porque a transcrição do depoimento pessoal do autor no acórdão recorrido contempla elemento fático hábil ao reconhecimento da confissão quanto à autonomia na prestação de serviços. Com efeito, o reclamante admite expressamente a possibilidade de ficar "off line", sem delimitação de tempo, circunstância que indica a ausência completa e voluntária da prestação dos serviços em exame, que só ocorre em ambiente virtual. Tal fato traduz, na prática, a ampla flexibilidade do autor em determinar sua rotina, seus horários de trabalho, locais que deseja atuar e quantidade de clientes que pretende atender por dia. Tal auto-determinação é incompatível com o reconhecimento da relação de emprego, que tem como pressuposto básico a subordinação, elemento no qual se funda a distinção com o trabalho autônomo. Não bastasse a confissão do reclamante quanto à autonomia para o desempenho de suas atividades, é fato incontroverso nos autos que o reclamante aderiu aos serviços de intermediação digital prestados pela reclamada, utilizando-se de aplicativo que oferece interface entre motoristas previamente cadastrados e usuários dos serviços. Dentre os termos e condições relacionados aos referidos serviços, está a reserva ao motorista do equivalente a $75 \%$ a $80 \%$ do valor pago pelo usuário, conforme consignado pelo e. TRT. $O$ referido percentual revela-se superior ao que esta Corte vem admitindo como bastante à caracterização da relação de parceria entre os envolvidos, uma vez que o rateio do valor do serviço em alto percentual a uma das partes evidencia vantagem remuneratória não condizente com o liame de emprego. Precedentes. Recurso de Revista conhecido e provido. (RR-1000123-89.2017.5.02.0038, $5^{\text {a }}$ Turma, Relator Ministro Breno Medeiros, DEJT 07/02/2020).

AGRAVO DE INSTRUMENTO EM RECURSO DE REVISTA INTERPOSTO PELA RECLAMANTE. ACÓRDÃO REGIONAL PUBLICADO NA VIGÊNCIA DAS LEIS N.S 13.015/2014 E 13.467/2017. PROCEDIMENTO SUMARÍSSIMO. RELAÇÃO DE EMPREGO. RECONHECIMENTO DE VÍNCULO. TRABALHADOR AUTÔNOMO. MOTORISTA. APLICATIVO. UBER. IMPOSSIBILIDADE. TRANSCENDÊNCIA JURÍDICA RECONHECIDA. NÃO PROVIMENTO. I. Discute-se a possibilidade de reconhecimento de vínculo de emprego entre motorista profissional que desenvolve suas atividades com utilização do aplicativo de tecnologia "Uber" e a sua criadora, Uber do Brasil Tecnologia Ltda. II. Pelo prisma da transcendência, trata-se de questão jurídica nova, uma vez que se refere à interpretação da legislação trabalhista $\left(\operatorname{arts.} 2^{\circ}, 3^{\circ}\right.$ e $6^{\circ}$, da CLT), sob enfoque em relação ao qual ainda não há jurisprudência consolidada no âmbito do Tribunal Superior do Trabalho ou em decisão de efeito vinculante no Supremo Tribunal Federal. Logo, reconhece-se a transcendência jurídica da causa (art. 896-A, $\S 1^{\circ}$, IV, da CLT). III. Na hipótese, o Tribunal Regional 
manteve, pelos próprios fundamentos, a sentença em que se reconheceu a condição de trabalhador autônomo do Reclamante. No particular, houve reconhecimento na instância ordinária de que o Reclamante ostentava ampla autonomia na prestação de serviços, sendo dele o ônus da atividade econômica. Registrou-se, ainda, a ausência de subordinação do trabalhador para com a Reclamada, visto que "o autor não estava sujeito ao poder diretivo, fiscalizador e punitivo da ré". Tais premissas são insusceptíveis de revisão ou alteração nessa instância extraordinária, conforme entendimento consagrado na Súmula n. 126 do TST. IV. A relação de emprego definida pela CLT (1943) tem como padrão a relação clássica de trabalho industrial, comercial e de serviços. As novas formas de trabalho devem ser reguladas por lei própria e, enquanto o legislador não a edita, não pode o julgador aplicar indiscriminadamente o padrão da relação de emprego. O contrato regido pela CLT exige a convergência de quatro elementos configuradores: pessoalidade, onerosidade, não eventualidade e subordinação jurídica. Esta decorre do poder hierárquico da empresa e se desdobra nos poderes diretivo, fiscalizador, regulamentar e disciplinar (punitivo). O enquadramento da relação estabelecida entre o motorista de aplicativo e a respectiva plataforma deve se dar com aquela prevista no ordenamento jurídico com maior afinidade, como é o caso da definida pela Lei n. 11.442/2007, do transportador autônomo, assim configurado aquele é proprietário do veículo e tem relação de natureza comercial. O STF já declarou constitucional tal enquadramento jurídico de trabalho autônomo (ADC 48, Rel. Min. Roberto Barroso, DJE n. 123, de 18/05/2020), a evidenciar a possibilidade de que nem todo o trabalho pessoal e oneroso deve ser regido pela CLT. V. O trabalho pela plataforma tecnológica e não para ela-, não atende aos critérios definidos nos artigos $2^{\circ}$ e $3^{\circ}$ da CLT, pois o usuário-motorista pode dispor livremente quando e se disponibilizará seu serviço de transporte para os usuários-clientes, sem que qualquer exigência de trabalho mínimo, de número mínimo de viagens por período, de faturamento mínimo, sem qualquer fiscalização ou punição por esta decisão do motorista, como constou das premissas fáticas incorporadas pelo acórdão Regional, ao manter a sentença de primeiro grau por seus próprios fundamentos, em procedimento sumaríssimo. VI. Sob esse enfoque, fixa-se o seguinte entendimento: o trabalho prestado com a utilização de plataforma tecnológica de gestão de oferta de motoristas-usuários e demanda de clientes-usuários, não se dá para a plataforma e não atende aos elementos configuradores da relação de emprego previstos nos artigos $2^{\circ}$ e $3^{\circ}$ da CLT, inexistindo, por isso, relação de emprego entre o motorista profissional e a desenvolvedora do aplicativo, o que não acarreta violação do disposto no art. $1^{\circ}$, III e IV, da Constituição Federal. VII. Agravo de instrumento de que se conhece e a que se nega provimento. (AIRR-10575-88.2019.5.03.0003).

As ementas acima colacionadas têm em comum identificação pelo órgão julgador de autonomia do prestador de serviços, além de ausência de subordinação, com falta de fiscalização de horários de trabalho e percepção de alto percentual sobre o valor da viagem.

Se tais julgados ainda não tem condições de criar jurisprudência pacífica ou mesmo majoritária sobre o tema no âmbito do TST, é servível como sério indicador do posicionamento a ser adotado.

Tal posicionamento diverge daquele adotado em outros Países, como a Inglaterra, por exemplo. E, muito embora não seja objeto desta pesquisa, por mero exercício de 
curiosidade, aponta-se julgamento da Corte Britânica, País que lida há mais tempo com aplicativos de transportes como a uber e, portanto, com mais experiência nesta modalidade de prestação de serviços e que deveria servir de paradigmas para a Justiça brasileira, no qual, ao contrário da nossa Alta Corte Trabalhista, reconheceu-se a existência da condição de empregado do motorista.

Sim, ao julgar a Reclamação Trabalhista "case n. 2202550/2015", contra a uber, o Tribunal do Trabalho Britânico, reconheceu que os motoristas de aplicativo eram empregados e não parceiros da plataforma, baseando-se na falta de liberdade do motorista para decidir sobre preço e a forma de oferta do seu trabalho.

Posto isto, respeitando entendimento divergente, passa-se a contraposição dos julgados pelo TST, cujas ementas estão acima transcritas, com finca no que dispõem a legislação brasileira e os princípios formadores do Direito do Trabalho.

\section{RELAÇÃO ENTRE MOTORISTA E UBER NA LEGISLAÇÃO BRASILEIRA E DIANTE DOS PRINCÍPIOS FORMADORES DO DIREITO DO TRABALHO}

Na forma do artigo $3^{\circ}$ da Consolidação das Leis do Trabalho, caracteriza-se a relação de emprego quando uma pessoa física, presta serviços de forma não eventual a empregador, sob a dependência deste e mediante salário. Portanto, para que se identifique relação de emprego em uma relação de trabalho, a prestação de serviços há de ser pessoal, não eventual, subordinada e onerosa (paga).

As características delineadas no item "3" deste estudo (A empresa uber), com as previsões contratuais e a prática cotidiana na relação entre motorista e uber revelam um contrato de emprego, como veremos a seguir. No entanto, não se nega que, quando se analisa a atuação do aplicativo, há uma sombra de dúvida sobre a figura típica do empregador prevista pelo artigo $2^{\circ}$ da Consolidação, na medida em que, em uma primeira impressão, quando a uber transfere os riscos e custos do negócio para o motorista, estaria se despindo da descrição contida no referido texto legal, porquanto é o empregador justamente o ente que não só admite, assalaria e dirige a prestação de serviços, mas também aquele que deveria assumir os riscos e custos do negócio.

Se todas as condições para, de um lado, reconhecer-se a condição de empregado e de relação de emprego, notadamente, pessoalidade, habitualidade, onerosidade e 
subordinação, estariam presentes, será que a transferência do ônus e risco do negócio, longe de afastar a figura do empregador, não estaria revelando um comportamento infracional do tomador dos serviços, que, ilegalmente, transfere ônus e obrigações legalmente suas para o contraente hipossuficiente?

Ora, aparentemente, os demais requisitos da relação de emprego não são de difícil identificação. A pessoalidade não é afastada pelo contrato, pelo contrário, o motorista, após ter seu cadastro aprovado para prestar serviços, ou seja, após ser admitido ( $\operatorname{artigo} 2^{\circ}$ da CLT), não pode se fazer substituir, já que o cadastro é nominal, com login e senhas pessoais.

Por outro lado, a flexibilização de horário de trabalho, com a possibilidade de motorista ficar offline, como equivale à ausência de habitualidade ou subordinação. Ora, o próprio artigo 443 da CLT, em redação dada pela Lei 13.467/17, indica a possibilidade de prestação de trabalho intermitente, ou seja, com alternância de períodos de prestação de serviços e inatividade, pelo que, a possibilidade de o motorista não ficar online ou com o aplicativo desligado, por si só, não afasta o contrato de emprego.

Assim como o inciso I do artigo 62 da Consolidação permite que um contrato de emprego preveja, como situação de exceção, a ausência de controle de jornada para a prestação de serviços externa, o que, nem por isso, deixa de ser o prestador um empregado. Por outro lado, quando a uber implementa bônus recompensatórios para o Motorista que se ativar em determinados horários, dias e regiões, evidentemente está a estabelecer exigências incompatíveis com trabalho eventual.

A onerosidade também não é de difícil percepção. O aplicativo fixa as tarifas cobradas do passageiro e a parte que cabe ao motorista. Irrelevante se o motorista recebe diretamente do passageiro ou por depósito do aplicativo, pois o pagamento se revela quando é o aplicativo que determina quanto e como o motorista vai receber pelo trabalho prestado, logo, pensamento diferente conduziria à ideia de que um vendedor externo, ao receber do cliente, repassando o valor da venda ao empregador, com a dedução das despesas e das comissões contratadas, deixaria de ser empregado.

Por fim, a subordinação, há ou não submetimento jurídico entre motorista e uber. A descrição do contrato e rotina de trabalho indicam que sim.

O contrato de prestação de serviços é de adesão, ou seja, é a uber quem estipula as condições para admissão e, apesar de não se fazer presente uma figura física de um gerente ou diretor fiscalizando a prestação de serviços, há a substituição por um algoritmo criado pelo 
tomador dos serviços que, sim, admite, fiscaliza e controla a prestação de serviços. De tal sorte, fiscalizado e controlado pelo aplicativo, o motorista, desde a admissão, se sujeita a padrões de conduta e vestimenta, podendo ser denunciado pelo passageiro por meio do próprio sítio da uber.

Também é notório o sistema de avaliação do Motorista pelos passageiros, que inclui, como se sabe, simpatia, educação, conhecimento das rotas e outros padrões de conduta e vestimenta. A avaliação ruim permite que a uber, como penalidade, desligue de forma unilateral o Motorista do aplicativo, revelando, com clareza solar, o poder hierárquico e disciplinador.

O aplicativo, por outro lado, se concede o poder de fixar o preço a ser cobrado para a viagem/transporte, retirando qualquer possibilidade de combinação de preço entre motorista e passageiro. Vejam que, apesar do contrato de adesão indicar que o valor apresentado pelo aplicativo é mera sugestão de cobrança mínima, fato é que o sítio do mesmo aplicativo indica campo para reclamações contra motoristas que tentam cobrar valores diferentes do que a uber informa ao passageiro.

Ao fixar valores para o transporte, a própria uber faz cair por terra o argumento de que seu produto de venda é o aplicativo e sua atividade é de intermediação, revelando que seu negócio é, indisfarçavelmente, de transporte de passageiros.

Por qualquer ângulo, portanto, verifica-se que a alardeada autonomia do motorista fica apenas no campo formal da relação, surgindo no campo da realidade a dependência econômica, a sujeição disciplinar e a subordinação estrutural, realçando-se como única diferença a substituição da subordinação conhecida ou tradicional por uma subordinação algorítmica.

Ademais, nunca é demais lembrar que a subordinação algorítmica ou telemática já prevista na legislação brasileira no Parágrafo Único do artigo $6^{\circ}$ da CLT, cuja redação foi dada pela Lei 12.551/2011.

Assim é que se os quatro primeiros elementos supracitados podem ser facilmente identificados na relação entre os motoristas e as empresas de tecnologia, a questão da subordinação adentra um cenário mais complexo, pois segundo os doutrinadores Leite, Sá e Costa Junior: 
Essa espécie de tecnologia disruptiva de mão de obra tem como característica a camuflagem do elemento subordinação, em contexto que evidencia o controle por meios remotos, decorrente da compreensão do teletrabalho. As alternativas que propõem o distanciamento do obreiro em relação à legislação vigente negam direitos fundamentais sociais vinculados ao direito humano ao labor em condições favoráveis, mínimas e dignas de subsistência. O respeito à normatividade protetiva e ao primado do emprego demandam a configuração do vínculo laboral entre o empreendimento e os correspondentes motoristas. (LEITE; SÁ; COSTA JUNIOR, 2018, p. 130).

Desse modo, é de clareza meridiana a ausência de uma subordinação clássica com a figura de um chefe, gerente, gestor, diretor ou qualquer outra configuração de superior hierárquico, com o exercício de comandos expressos. Contudo, o monitoramento através do aplicativo manifesta uma forma de controle ainda mais intensa e rigorosa, pois essa nova configuração é possível a partir do desenvolvimento de novas tecnologias móveis, sendo denominadas como uma espécie de "subordinação algorítmica".

\begin{abstract}
Afinal, já não é mais necessário o controle dentro da fábrica, tampouco a subordinação a agentes específicos ou a uma jornada rígida. Muito mais eficaz e repressor é o controle difuso, realizado por todos e por ninguém. Neste novo paradigma, os controladores, agora, estão espalhados pela multidão de usuários e, ao mesmo tempo, se escondem em algoritmos que definem se o motorista deve ou não ser punido, deve ou não ser descartado. (MARTINES, 2017).
\end{abstract}

Destarte, como já apontado, faz-se importante ressaltar novamente que a empresa Uber possui uma gama de regramentos, os quais preveem diversas situações que poderão culminar com o desligamento temporário ou definitivo de seus motoristas, que são explícitas em documento publicado no portal da empresa, denominado por "Políticas de Desativação", cujo enunciado aduz que "durante sua parceria conosco, existem políticas e regras que você deve cumprir para permanecer habilitado na plataforma", dentre as quais se destacam:

$1^{\circ}$ ) Manter uma média de avaliação por parte dos usuários da plataforma abaixo da média de avaliação da cidade; $2^{\circ}$ ) Ficar online no aplicativo sem estar disponível para iniciar a viagem e se locomover para buscar o usuário não é uma conduta aceitável; $3^{\circ}$ ) Sugerir ou solicitar aos usuários uma determinada avaliação; $4^{\circ}$ ) Aceitar viagens e ter uma taxa de cancelamento maior do que a taxa referência da cidade nas quais atua o Motorista Parceiro; $5^{\circ}$ ) Ficar online na plataforma e ter uma taxa de aceitação menor do que a taxa referência da cidade na qual atua o Motorista Parceiro. (UBER, [s.d.])

Em consonância ao entendimento do doutrinador Delgado (2017, p. 91), "a subordinação é o conceito que traduz a situação jurídica derivada do contrato de trabalho 
mediante o qual o empregado se obriga a acolher a direção do empregador sobre o modo de realização da prestação de serviços". Ora, essas novas ferramentas tecnológicas acabam, pois, disfarçando os métodos de controle.

\begin{abstract}
A plataforma não faz apenas intermediação entre passageiro e motorista, mas presta um serviço de transporte. Desse modo, estando presentes todos os elementos fáticosjurídicos da relação de emprego entre a Uber e seus motoristas, ressaltando, quem define o preço do serviço, o pagamento realizado ao trabalhador, e as penalidades aplicadas aos motoristas que atuarem de forma contrária as regras estabelecidas, é somente a empresa. Por fim, este novo modelo de exploração dos trabalhadores tem de ser reconhecido como uma relação de emprego, já que a empresa não cumpre suas obrigações como empregador. E na hipótese do não reconhecimento do vínculo, a tendência será o aumento das reclamações trabalhistas envolvendo as condições impostas aos motoristas. (SILVA, 2017).
\end{abstract}

A empresa Uber, todavia, ainda é resistente em sua tese sobre não empregar nenhum motorista, passando a impressão de que apenas fornece um serviço de tecnologia para que os trabalhadores empreendedores possam desenvolver sua atividade, dando a falsa sensação de que os motoristas são autônomos.

Todavia, a empresa promove um sistema de promoções, proporcionando um programa de metas aos motoristas, o que caracteriza modelo de gestão empresarial, de modo a encobrir a natureza de vínculo empregatício, com o propósito de anular a proteção dos trabalhadores.

Verifica-se, pois, que a plataforma é o instrumento que comanda, controla e supervisiona a prestação de serviços, tornando insubsistente a ideia de que há prestação de serviços pelo aplicativo e não para o aplicativo, posto que o motorista presta serviço de transporte fiscalizado e gerenciado, sendo que a plataforma determina, de forma unilateral, todos os termos e condições em que o serviço é prestado.

Remanesce, no entanto, verificar se o aplicativo, ao transferir para o motorista os riscos e custos do negócio, despe-se da condição de empregador prevista no artigo $2^{\circ}$ da CLT. Neste aspecto, é plenamente aplicável o artigo $9^{\circ}$ da CLT, em complementação ao caput do artigo $2^{\circ}$ ora citado. Sim, pois, há clara transferência ilegal dos riscos e custos do negócio, porquanto configurada a condição de empregado do motorista, com o preenchimento dos requisitos do artigo $3^{\circ}$ da CLT, o aplicativo acaba por implementar cláusula contratual nula de pleno direito, que tenta desvirtuar sua condição de empregador e impedir a aplicação das normas protetivas contidas na CLT. 
Não se pode olvidar, ainda, dos princípios garantidores, que foram o Direito do Trabalho.

No entendimento de Alice Monteiro de Barros (2012, Curso de Direito do Trabalho, p. 142), o Princípio da Norma Mais Favorável, como uma das espécies do Princípio da Proteção, sustenta a aplicação da norma mais favorável ao trabalhador, independentemente da hierarquia, daí porque em contrato de trabalho, presentes os requisitos legais da relação de emprego, prevista pelo artigo $3^{\circ}$ da CLT, a aplicação deste texto legal na relação de direito material é inafastável.

Ressalte-se, ainda, que há sucumbimento das cláusulas contratuais previstas no contrato de adesão diante do Princípio da Primazia da Realidade sobre a forma, pelo que os aspectos formais previstos nos instrumentos contratuais não subsistem quando a situação fática revela uma relação de emprego, pouco importando a denominação que as partes contraentes tenham dado ao relacionamento havido (art. $9^{\circ}$ da CLT).

Por fim, a adesão voluntária e espontânea do motorista ao contrato de adesão, por si só, não afasta a condição de empregado, dado ao Princípio da Irrenunciabilidade que limita a autonomia da vontade das partes, subordinando-se às normas de ordem pública e, portanto, cogentes, que tutelam o trabalhador hipossuficiente na relação contratual.

\section{CONCLUSÃO}

Este artigo teve como objetivo analisar a relação entre a chamada "Revolução 4.0" e o motorista de aplicativo uber enquanto profissional para maior compreensão das lacunas deixadas na legislação que regulamenta os direitos do trabalhador. Primacialmente, notou-se que foi desenvolvido um contexto de livre mercado, com uma plataforma gerenciado a prestação de serviços com fiscalização rigorosa, impingindo medo e receio no trabalhador, que não tem alcance ao método de avaliação e nem defesa contra si próprio, restando à mercê da instabilidade laboral - e consequentemente financeira.

Paralelamente demonstrou-se que, almejando ocultar a percepção do vínculo empregatício do motorista de aplicativo, os agentes da uberização passaram a se alimentar dos denominados intermitentes globais que, por sua vez, colocam-se em situação de permanente disponibilidade. 
É possível enxergar novos instrumentos de gerência e fiscalização da prestação de serviços, com subordinação do trabalhador a um algoritmo, a uma plataforma que controla e impõe demandas aos empregados, às vezes muito mais rigorosas e severas do que um gerente ou chefe pessoa física, afastando-se completamente da relação o sentimento humano da empatia.

O que a plataforma exige é a prestação de serviços, tornando secundária a preocupação com a segurança e saúde do trabalhador. O lucro é a única finalidade e a avaliação por notas dadas ao prestador de serviços e seu tempo de disponibilidade, constituem os números frios que determinarão a continuidade do trabalho ou a punição com o desligamento e desemprego.

Não a toa, percebe-se que o aplicativo joga com percentuais de participação nas tarifas de viagem, que ele mesmo fixa, empurrando o risco e ônus do negócio para o hipossuficiente na relação, ficando apenas com o lucro, que permite à uber se tornar a maior empresa de transporte e aluguel de veículo no mundo, mesmo sem possuir frota própria.

Não se trata daquela ideia utópica do Vale do Silício, na qual a internet serviria para conectar consumidores-clientes com prestadores de serviços. Não. Da alternativa sustentável surgiu nova forma de atividade econômica. Novo comércio, onde se permite uma atividade lucrativa em um mercado hostil e sem regulamento, expondo ao risco trabalhadores que antes estavam dentro de uma esfera de proteção legal e contratual, como bem apontou Tom Slee.

Não se alteraram as forças e nem a dinâmica da relação comum de emprego. Apenas o empreendedor/empregador físico recebeu novo formato. Uma forma virtual e impessoal de trato, que demanda cada vez mais mão de obra, sem contrapartida social ou financeira.

Tudo isso por trás de um discurso de modernidade. A tecnologia vem para o progresso da sociedade. O trabalhador agora pode escolher quando trabalhar. No entanto, na prática, verifica-se que se a fonte de subsistência alimentar é o trabalho e se este é remunerado por demanda, não há como o trabalhador recusar serviço ou limitar sua jornada. De tal sorte, há apenas a criação de um muro o véu protetor para o empregador no debate contínuo entre capital e trabalho, onde o empregado não tem mais acesso ao empregador físico, mas apenas ao virtual representado pela plataforma.

Ante todo o exposto, percebeu-se que é inevitável a interferência do Estado, seja na produção de normas que regulem essa nova forma de prestação de serviços, sejam na intervenção do Judiciário, cumprindo seu papel de intérprete da Lei para a promoção da 
Justiça, sempre com olhos ao princípios formadores do Direito do Trabalho e na legislação protetiva já positivada, de forma a tornar justa a interação entre mercado, lucro e o bem social.

Conclui-se, ainda, que urge a evolução das discussões judiciais, provocando inéditas decisões do Tribunal Superior do Trabalho e, finalmente, o reconhecimento do Motorista de Aplicativo com empregado da UBER e de outras plataformas semelhantes, como forma de respeito à dignidade e segurança do trabalhador.

\section{REFERÊNCIAS}

ANTUNES, Ricardo. O privilégio da servidão. São Paulo: Boitempo, 2018.

ANTUNES, Ricardo. Os sentidos do trabalho: ensaio sobre a afirmação e a negação do trabalho. São Paulo: Editora Boitempo, 1999. p. 31-32.

BOUDAUD, Veronique G. What does Uberization mean?. 30 nov. 2016, Linkedin.www.linkedin.com/pulse/what-does-uberization-mean-veroboudaud. Acessado por último em 22 de março de 2021.

BRASIL. Decreto-Lei n. 5.452, de $1^{\circ}$ de Maio de 1943. Aprova a Consolidação das Leis do Trabalho. Rio de Janeiro, Maio de 1943.

BARROS, Alice Monteiro de. Curso de Direito do Trabalho. 8. Ed. LTr, 2012.

CASSAR, Vólia Bomfim. Direito do trabalho. 10. ed. São Paulo: Método, 2014.

DELGADO, Mauricio Godinho. Curso de Direito do Trabalho. São Paulo: LTr, 2012.

GANSKY, L. The mesh: Why the future of business is sharing. New York: Portfolio Penguin, 2010. 
LEITE, Yuri Bindá; SÁ, Emerson Victor Hugo Costa de; SOUZA JÚNIOR, Albefredo Melo de. Natureza jurídica do vínculo entre os motoristas e a empresa Uber: trabalho autônomo ou relação de emprego? Laborare, ano 1, n. 1, p. 129-150, Julho/2018.

MARTINES, Fernando. Juiz reconhece vínculo de emprego com Uber e cunha termo "uberização". Conjur, 14 fev. 2017. Disponível em: https://www.conjur. com.br/2017-fev14/juiz-reconhece-vinculo-emprego-uber-cunha-termouberismo. Acesso em: 23 mar. 2021.

OLIVEIRA, Carol; KARIN, Salomão; FONSECA, Mariana; FLACH, Natália. Tudo no Aplicativo. Revista EXAME, n.1183, 17 de abril de 2019. Disponível em: < https://docs.wixstatic.com/ugd/3d9e82 430595dd43b24eecb422a54c4a0f2d9c >.Acesso em: 22 de março de 2021.

SCHOR, J. Debating the sharing economy. Great Transition Iniciative, 2014. Disponível em: < https://greattransition.org/publication/debating-the-sharing-economy>. Visto por último em: 22 de março de 2021.

SCHWAB, Klaus. A Quarta Revolução Industrial. São Paulo: Edipro, 2016.

SHIRKY, C. Lá vem todo mundo: o poder de organizar sem organizações. South Carolina, North Charleston: Create Space Independent Publishing Platform, 2008.

SILVA, Gabriel Leal Barbosa. UBER x motorista: possibilidade de configuração de relação de emprego. Conteúdo Jurídico, Brasília-DF: 11 dez. 2017. Disponível em: http://www.conteudojuridico.com.br/?artigos\&ver=2.590123. Acesso em: 23 mar. 2021. SOUSA, Euzébio Jorge Silveira de. O desemprego da juventude no Brasil em crise. Juventude.br, São Paulo, v. 1, p. 66, 2018.

SLEE, Tom. Uberização: a nova onda do trabalho precarizado. São Paulo: Editora Elefante, 2017.

SUNDARAJAN, Arun. The Sharing Economy: the end of employment and the rise of crowd-based capitalism. Cambridge, MA: The MIT Press, 2016. 
Sítio do Tribunal Superior do Trabalho - www.tst.jus.br. Acesso em: 15 fev. 2021.

UBER. About. Disponível em: https://www.uber.com/br/pt-br/about/. Acesso em: 23 mar. 2021.

Sítio CONJUR - disponível em uber-inglaterra-vinculo https://www.conjur.com.br/dl/uberinglaterra-vinculo-motoristas.pdf -motoristas.pdf (conjur.com.br). Acesso em: 15 fev. 2.021. 